\title{
Effects of the Reactive Power Injection on the Grid-The Rise of the Volt/var Interaction Chain
}

\author{
Albana Ilo \\ Institute for Energy Systems and Electrical Drives, TU Wien, Vienna, Austria \\ Email: albana.ilo@tuwien.ac.at
}

Received 6 July 2016; accepted 26 July 2016; published 29 July 2016

Copyright (C) 2016 by author and Scientific Research Publishing Inc. This work is licensed under the Creative Commons Attribution International License (CC BY). http://creativecommons.org/licenses/by/4.0/ (c) (i) Open Access

\section{Abstract}

The major challenge to increase the decentralized generation share in distribution grids is the maintenance of the voltage within the limits. The inductive power injection is widely used as a remedial measure. The main aim of this paper is to study the effect of the reactive power injection (by whatever means) on radial grid structures and their impact on the voltage of the higher voltage-level grids. Various studies have shown that, in addition to the major local effect on the voltage at the injection point, the injection of the reactive power on a feeder has a global effect, which cannot be neglected. The reactive power flow and the voltage on the higher voltage level grid are significantly affected. In addition, a random effect is introduced by the DGs which are connected through inverters (using wind or PVs). Although their operation is in accordance with the grid code, a volatile reactive power flow circulates on the grid. Finally, this study proposes the implementation of the "Volt/var secondary control" interaction chain in order to increase the distributed generation share at every distribution voltage level, be it medium or low voltage, and at the same time to guarantee a stable operation of the power grid. Features of Volt/var secondary control loops ensure a resilient behavior of the whole chain.

\section{Keywords}

Distributed Generation, LINK-Architecture, Smart Grid, Transmission Grid, Volt/var Control, Volt/var Interdependencies

\section{Introduction}

The technology progress has given rise to a rapid growth in the utilization of distributed generations, DG. How- 
ever, this trend was unable to prevail for a long time because it failed to comply with the electric power quality parameters. Cases of voltage violation have been identified in the distribution network [1]-[5], while a decrease of the static and dynamic security has been discovered in the transmission grid [6]. The coordinated operation of the transmission and distribution systems has now become more and more difficult [7] [8].

Nowadays, it has become quite clear that the reactive power support on the distribution grid is necessary when utilizing DGs [9] [10]. Normally, this is injected by using an uncoordinated local controlled reactive device, which creates an uncontrolled reactive power flow on both transmission: i.e. very high and high voltage grid (VHVG, HVG), and distribution grid: i.e. medium voltage grid (MVG), and low voltage grid (LVG). Originally, the uncontrolled reactive power flow on the distribution grid increases slowly and imperceptibly. Therefore, it is not ascertained any visible impact on the transmission grid [11] [12]. Later, when the DG share increases, the reactive power flow creeps dangerously into the transmission grid, thus creating an uncontrolled reactive power flow on HVG [13]. Their operation was experiencing big uncertainties [6] [9]. The study of mitigation of the voltage rise via the reactive power absorption from distributed photo voltaic (PV), inverters underlined the high significance of the substantial amount of extra reactive power that is absorbed by the feeder at the substation. Reference [14] underlines the necessity of its compensation without performing any deep and broad analysis of the created situation. While Reference [15] highlights only the local effect of the reactive power on LVG feeders. Currently, this area is not investigated deeply enough and different rules have been outlined in order to handle it properly [16]. However, due to the high complexity of the phenomena, only very general re-commendations can be made [7].

Traditional Volt/var control technologies have been used by utilities to coordinate the transformer step settings and the reactive power devices. These technologies are developed and introduced for different voltage levels, i.e. high voltage level [17]-[20] and medium voltage level [21]-[28]. With the increasing of DGs share, Volt/var control technologies have proved to be necessary also in LVG [29] [30]. Nevertheless, these technologies have been developed so far independent of each other. In those conditions, a smooth, resilient Volt/var control over the all-voltage levels grids is difficult.

This paper is organized in two parts. The first part looks into the reactive power injection, by whatever means, on the radial grid structures and their impact on the voltage of the higher voltage-level grids. The paper also studies the role of the on-load tap change, OLTC, of the intermediate transformer. It later analyzes the reasons of the uncontrolled reactive power flow on the higher voltage-level grids resulting from the DGs. The study finds the need to control the reactive power flow, which circulates across the power grid, of great interest and its second part describes the Volt/var secondary control, which is newly introduced on a large scale throughout the different regions or portion of the grids and is used as a sustainable, resilient and base interaction instrument. The chain of Volt/var secondary control loops is set over all-voltage levels (high, medium and low) and even over the costumer plants (CP). This kind of chain introduces, for the first time in power systems, a new cross functional application in real time, which provides significant benefits over the traditional implementations. The resilient chain of Volt/var secondary control loops is built on the LINK-based architecture [31]. The study also deals with new features of the Volt/var secondary control.

\section{Effects of the Reactive Power Injection into Radial Grid Structures}

To understand the shortcomings of current practices and to identify possible improvements to the grid, this study presents a series of performed simulations. They are restricted on European power system types.

\subsection{Structure of European Power Systems}

Simulations have been performed on a medium voltage test grid of European Style [32]. Those grids are balanced and symmetrical, therefore their behavior was studied by calculating only one phase. They have mostly three phase, three conductor structure and have a mixture of overhead lines and underground cables. Transformers between medium and low voltage level have fix tap position, while transformers between high and medium voltage level have normally on load tap changer, OLTC.

In European power systems transmission system operator (TSO) is responsible for the operation of transmission grid; i.e. VHVG and HVG (... $400 \mathrm{kV}, 220 \mathrm{kV})$, while, distribution systems operator (DSO) is responsible for the operation of the sub-transmission and distribution grid; i.e. HVG (110 kV), MVG (66 kV, $30 \mathrm{kV}, 10 \mathrm{kV}$, $6 \mathrm{kV})$ and LVG $(0.4 \mathrm{kV})$. 


\subsection{Definitions}

Through the whole paper are used the terms local and global effect, which are defined as follows:

"Local effect" means that the biggest effect upon voltage can be observed directly at the point of reactive power injection, which disappears then over the same feeder. Conversely, "global effect" means that the effect of reactive power injection upon voltage occurs in more remote parts of the grid i.e. on other feeders and even on higher voltage level grid parts.

\subsection{Volt/var Interdependencies between Different Voltage Levels}

In order to study the impact of reactive power injection on radial grid structures and on the voltage of the higher voltage-level grids a 33/11 kV test grid connected through a $20 \mathrm{MVA}$ transformer is used. Figure 1 shows its one-line diagram and the corresponding voltage profiles. Figure 1(a) shows the test grid connected through a transformer which has fix tap position. To simplify the calculations, one $33 \mathrm{kV}$ line with a distributed load and supplying feeder has been modelled (see Appendix A). On the $10 \mathrm{kV}$ bus bar are connected two feeders: feeder 1 and feeder 2. An $8 \mathrm{MW}$ lumped generator is connected to Feeder 1 and it represents all distributed generators connected on this feeder. Loads are modelled by means of polynomial equations of the second degree (see Appendix A). Figures 1(b)-(d) show the voltage profiles at one point on the daily load curve, say at peak load, for the supplying feeder and both feeders 1 and 2. Two cases, A and B, are simulated. In case A, the generator injected only active power; reactive power was set zero, $Q=0$ Mvar. In case B it was injected active power and simultaneously was consumed reactive power, Qinductive $=3.0$ Mvar. Results show that in case B, the voltage profile for feeder 1 at the connection point of the generator was pushed down from $12.228 \mathrm{kV}$ to $10.755 \mathrm{kV}$, Figure 1(c). That means the voltage was decreased by $1.473 \mathrm{kV} ; 13.39 \%$. This corresponds to the major, local effect of the reactive power to the voltage. In the same figure can be seen also a global effect. The voltage on the $11 \mathrm{kV}$ bus bar is displaced from $11.540 \mathrm{kV}$ to $10.88 \mathrm{kV}$, that means it is decreased by $0.66 \mathrm{kV}$; 6\% (Appendix B). This effect can be observed in Figure 1(b) and Figure 1(d) as well. The global effect impacts also feeder 2 although there was not injected reactive power. Additionally, this effect is lead over on the high voltage side of the transformer (Figure 1(b)). Voltage on the bus bar is decreased by $1.244 \mathrm{kV} ; 3.77 \%$, because the reactive power flow through the transformer was increased from 5.45 Mvar in case A to 8.94 Mvar in case B. Results show that the global effect on high voltage side of the transformer is smaller, about $3.77 \%$, than on low voltage side, about $6 \%$.

Figure 2 shows effects of tap's and var's on voltage profile on MVG. Figure 2(a) shows the electrical schema which comprises one HV/MV transformer, two feeders A and B. In feeder A are connected two DGs, while in feeder B are not connected any. Figure 2(b) shows the lonely effect of the tap's on the voltage profile. Bold lines show the normal voltage profiles of feeders A and B, while dashed lines show the voltage profiles after the

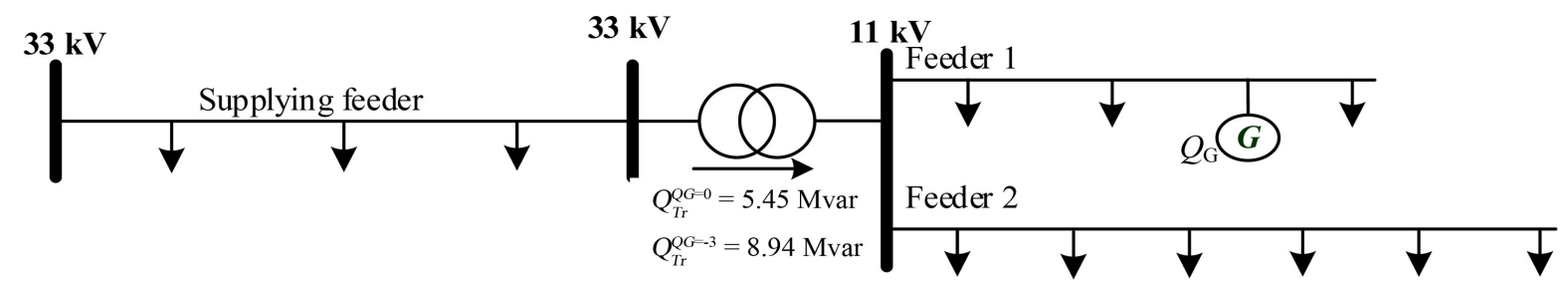

(a)

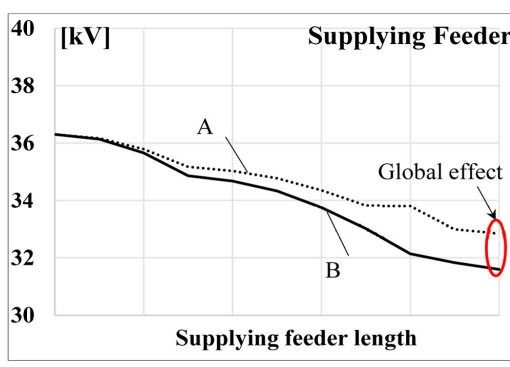

(b)

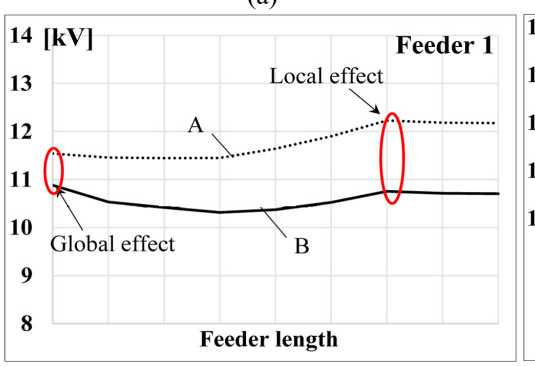

(c)

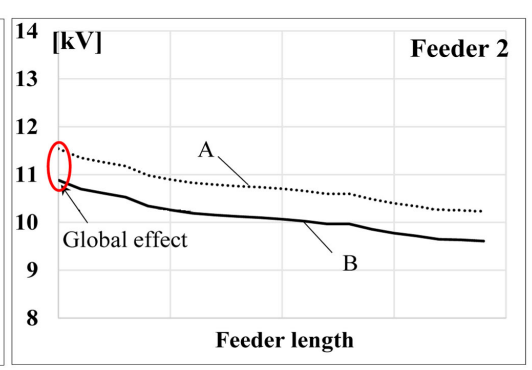

(d)

Figure 1. Simplified test feeders for the Volt-var interdependency study and the corresponding voltage profiles in the case the transformer has fix tap position. 
(a)

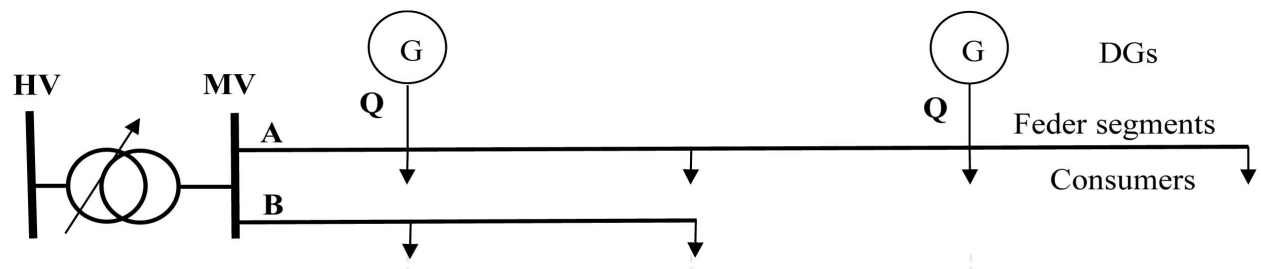

(b) Trartep
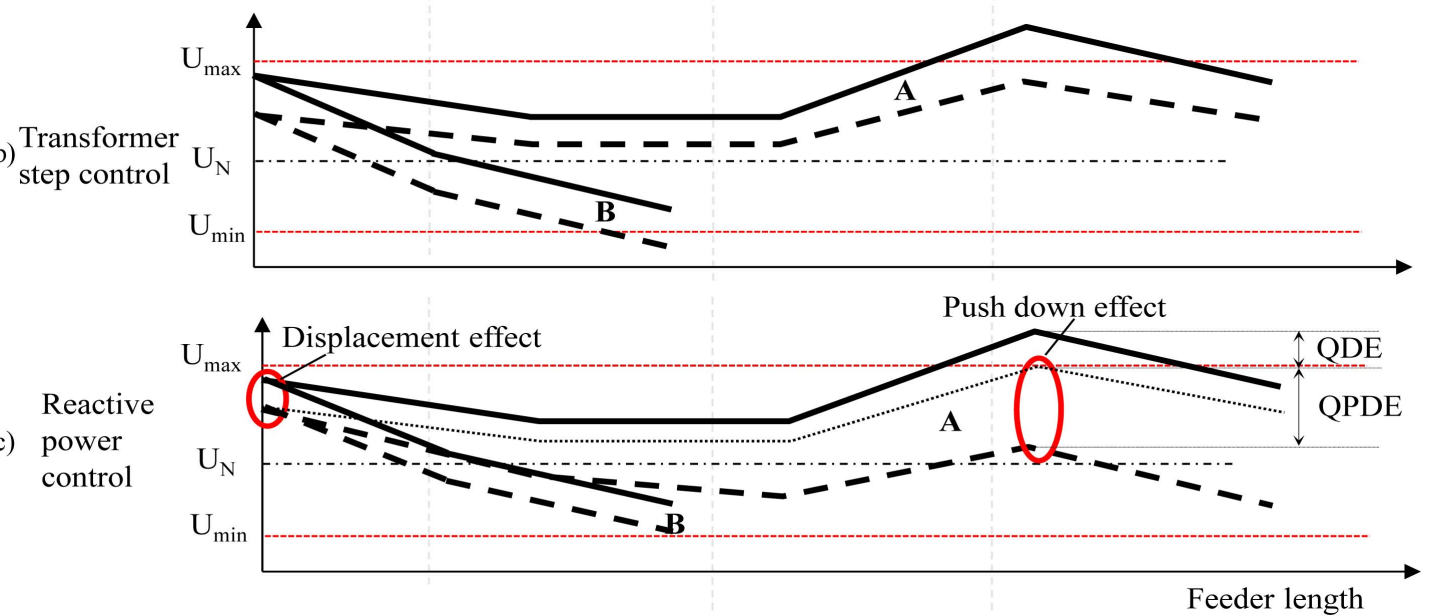

Figure 2. Effects of tap's and var's on voltage profile on MVG: (a) Electrical schema; (b) Transformer step control; (c) Reactive power control.

tap's change. The change of tap position shifts/displace the voltage profile mainly in parallel to the original one. The dashed lines in Figure 2(c) show the lonely effect of the var's on the voltage profile. The impact of var's control on voltage consists of two effects:

- "Displacement effect" is shifting the voltage at the supply bus bar and as a consequence the voltage profile in parallel with the original one. It produces the same effect as tap changers. This effect is also called global effect because it is affecting the voltage of all feeders connected on this bus bar.

- "Push down effect" is suppressing the voltage on the injection point. This effect is called also local effect because it is affecting only the feeder where is injected reactive power.

Voltage change, $\Delta U_{k}^{\mathrm{QE}}$, at the connection point of the $k^{\text {th }}$-DG caused by the reactive power injection can be calculated by (1).

$$
\Delta U_{k}^{\mathrm{QE}}=\Delta U_{\mathrm{LVs}}^{\mathrm{QDE}}+\Delta U_{k}^{\mathrm{QPDE}}
$$

where $\Delta U_{\mathrm{LVs}}^{\mathrm{QDE}}-$ Voltage change at the low voltage, $\mathrm{LV}$, bus bar of the transformer caused by the displacement effect of the reactive power injection.

$\Delta U_{k}^{\mathrm{QPDE}}-$ Voltage change at the connection point of $k^{\text {th }}$ DG caused by the push down effect of the reactive power injection.

Figure 3 shows the simplified test feeders for the Volt-var interdependency and the corresponding voltage profiles when transformer has OLTC. Its voltage set point was set to $11.5 \mathrm{kV}$. The same scenario as described above was simulated. In case A, only active power $P=8 \mathrm{MW}$; $=0$, was injected. In case $\mathrm{B}$, reactive power was injected $Q=3$ Mvar additional to the active power. OLTC acted and the tap position was changed from 10 to the limit position, 0 , by defeating the "displacement/global effect" on the lower voltage side of the transformer $\Delta U_{\mathrm{LVs}}^{\mathrm{QDE}}=0$, Figure 3(c) and Figure 3(d). The local effect of the reactive power injection is equally with the push down effect and is reduced to $\Delta U_{k}^{\mathrm{QPDE}}=0.885 \mathrm{kV}, 8.0 \%$. It is $5.39 \%$ smaller than in the case the transformer had fixed tap position. Reactive power flow through the transformer has reached a value of 9.118 Mvar. This is a slight increase of the reactive power flow, about $2 \%$, compared to the fix tap position case. The global effect on transformer high side marks a value of $1.328 \mathrm{kV}$; $4.18 \%$. This is a slight increase, about $0.41 \%$, compared with the fix tap position case. Higher voltage along the $33 \mathrm{kV}$ feeder means higher capacitive power injection on the feeder which is even more evident on cable structures. But normally this effect is attenuated by the increase of the reactive power consumption of the loads, which have a particular load-voltage characteristic. 


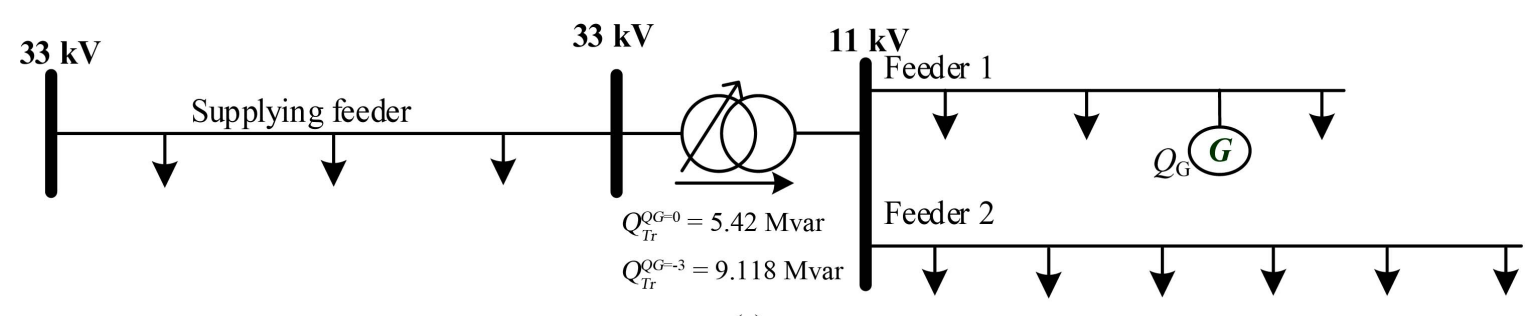

(a)

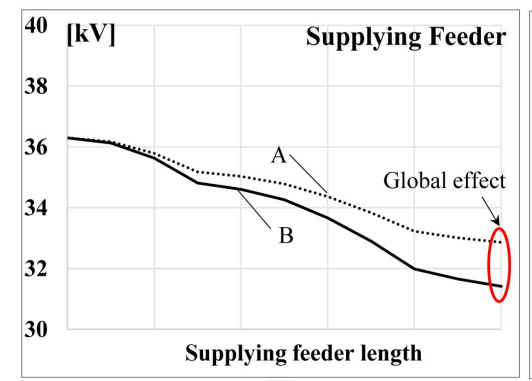

(b)

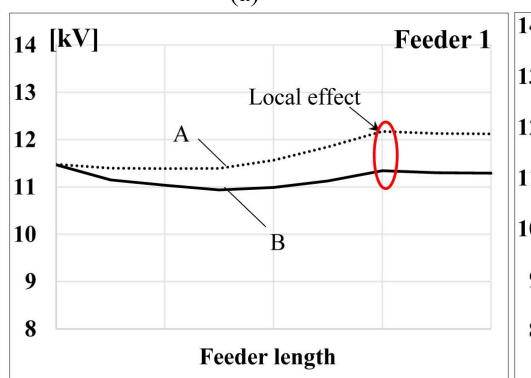

(c)

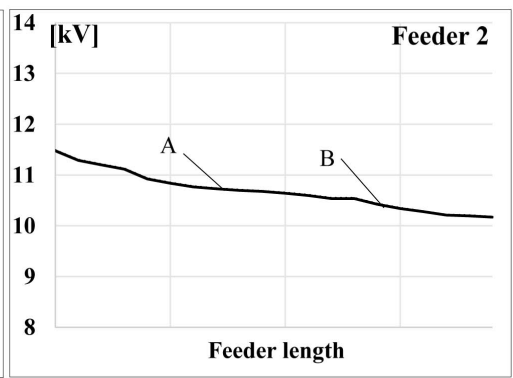

(d)

Figure 3. Simplified test feeders for the volt-var interdependency study and the corresponding voltage profiles in the case the transformer has OLTC.

Summarizing, the global effect of the reactive power injection in radial structures at higher voltage levels is always present, and is independent of the fact whether the in-between transformers have OLTC or not.

Transformers between high and medium voltage grids have usually OLTCs. The uncoordinated, local control of the reactive power, especially by high DG share, creates an uncontrolled reactive power flow in high voltage grid which influences the voltages on the grid in an unpredictable way. The boosted global effect exists only at high voltage grid. Additionally, depending on the static parameters of the MV grids (susceptance) and the loadvoltage behavior transformer steps can be moved to their limits. The displacement/global effect in medium voltage feeder head bus bars is annihilated by the OLTC action, while the local effect on the injection point is reduced.

Transformers between medium and low voltage are usually operated with fix tap position. The uncoordinated, local control of the reactive power especially by high DG share, creates an uncontrolled reactive power flow in medium voltage grid which influences the voltages on the grid in an unpredictable way. The global effect exists both in medium and low voltage grid. The reactive power injection in low voltage has the biggest possible local effect.

\subsection{Uncontrolled Reactive Power Flow}

Besides the local effect, the injection of reactive power in radial structures has also a considerable global on the voltage-landscape of the higher voltage level grid, the Displacement Effect. This effect is attributed to the injected reactive power, which flows uncontrolled through the transformer into higher voltage level grid.

Figure 4 shows an overview of HVG and MVG connected through the HV/MV transformer. In MVG are presented schematically all electrical devices, which may be used to inject reactive power like capacitors and different types of DGs; i.e. CHP, Run of river, Wind and PV. $\Delta Q_{s}^{\mathrm{MVG}}$ presents the additional reactive power, which flows through the transformer into HVG. The management of the Displacement Effect on the higher voltage level is obvious in case of capacitors, which usually are installed on overhead line feeders. Their number is normally restricted to maximal four or five capacitors per feeder. Capacitor banks can be switched on or off manually, or through a local controller. TSOs and DOSs are aware of their effect, and the grid operation is adjusted accordingly. TSOs investigate the "Displacement Effect" by means of off-line power flow. Figure 5(a) shows a capacitor, which is operated by a local control device and its effect on the discrete injection of reactive power into the grid.

In presence of high DG share, $\Delta Q_{s}^{\mathrm{MVG}}$ is injected into the grid by DGs, which have a local reactive power control device. The reactive power, which DGs can inject into their connection points, is defined by the rules laid down in Grid Code; Distribution Connection Condition. DGs operation with a fix $\cos \phi$, creates an uncontrolled 


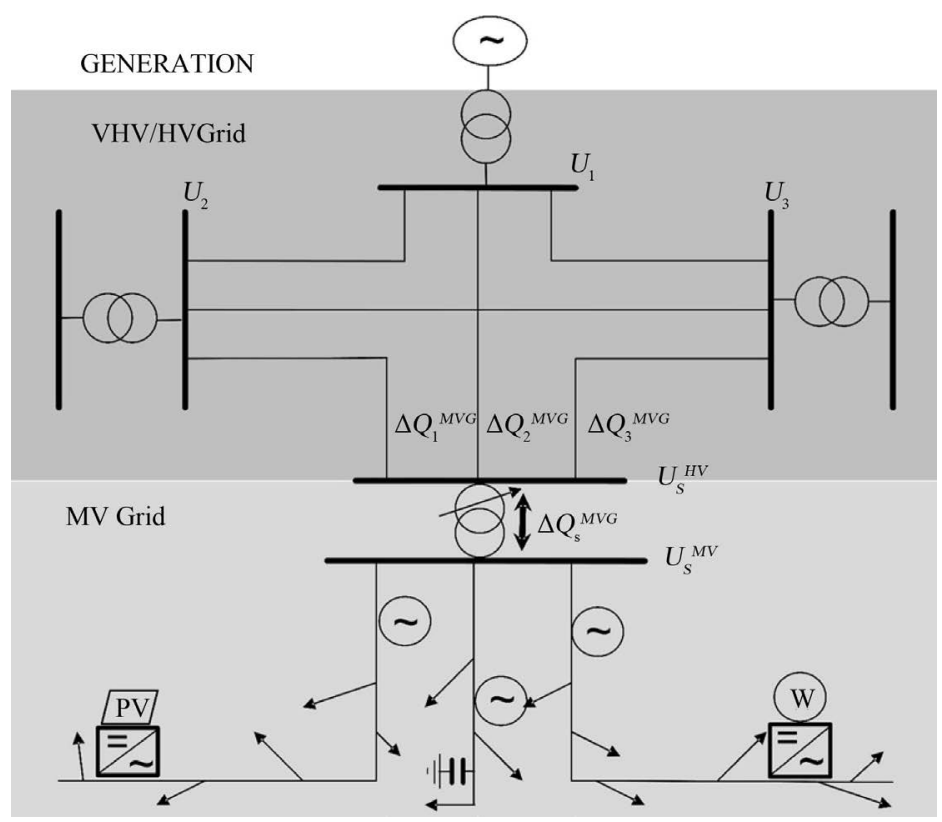

Figure 4. Uncontrolled reactive power flow through HV/MV transformer.
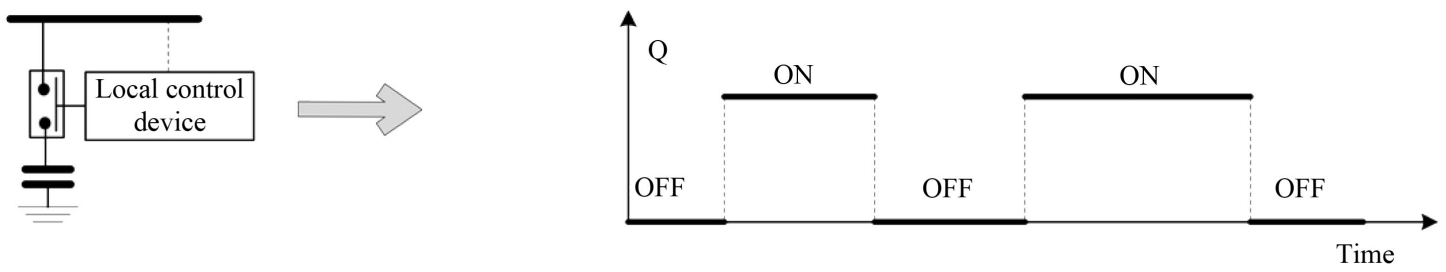

(a)
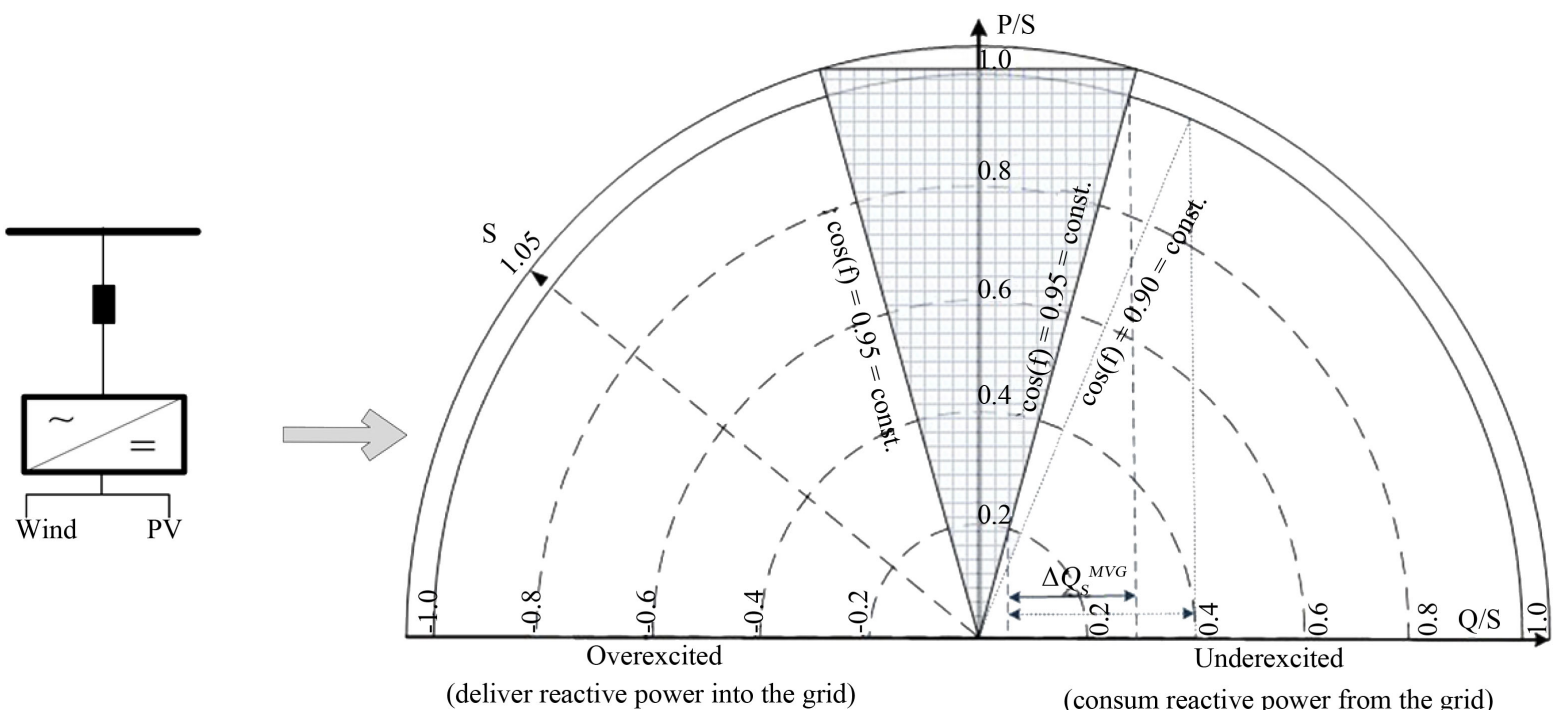

(b)

Figure 5. Reactive power diagrams of different devices: (a) capacitors; (b) inverters.

reactive power flow on HVG [6]. Additionally, the amount of injected reactive power depends on the PQ diagrams of the generating unit or inverter. Figure 5(b) shows the PQ diagram of an inverter (PV, Wind). The inverter is set to inject active power into the grid at a constant power factor of 0.95. All units that are using volatile energy resources are characterized by a fluctuating active power generation. Being operated with a constant 
power factor, the fluctuation of the active power will be passed over to the reactive power, i.e. for a power factor of 0.95 , an active power fluctuation of $80 \%$ provokes a fluctuation of the reactive power, $\Delta Q_{s}^{\mathrm{MVG}}$, of about $20 \%$. TSOs are not aware of this reactive power flow, which flow uncontrolled into the HVG. Consequently, they cannot define any countermeasures in advance. [4] proposes to extent power factor limits 0.95 inductive/capacitive to 0.9 inductive/capacitive. This step will produce a larger uncontrolled, additional reactive power amount in the HVG [6], i.e. for a power factor of 0.90 , an active power fluctuation of $80 \%$ provokes a variation of the reactive power on the HVG, $\Delta Q_{s}^{\mathrm{MVG}}$, of about $35 \%$. That means by the same active power fluctuation the uncontrolled reactive power flow increases by $75 \%$.

In conclusion, the DG integration causes an uncontrolled reactive power flow on HVG, even when the Distribution Connection Condition rules [16] in MVG are respected.

\section{The Rise of Volt/var Control Chain}

Every change in power systems, be in grid configuration or in power injection or consumption has an impact on its behavior. The impact scale depends on the structure of the network, on the position of the change point or area, and on its own amount and extension. Therefore, a small DG share doesn't have an obvious impact on the power system behavior. Contrarily, a large DG share effects significantly their behavior. Voltage limits on radial structures are violated, uncontrolled reactive power flows in the higher voltage grids. All these make the reliable and stable operation of power systems more and more difficult. Coordinated measures across all grid parts are necessary to cope with the new situation of large DG scale. Therefore, Volt/var secondary control is newly introduced on a large scale throughout the different regions or parts of the grid. Volt/var secondary control is used as a sustainable, resilient, base interaction instrument between different parts of the grid.

\subsection{Power System Holistic Model}

Figure 6 shows a global outline of an interconnected power system [31] [33]. HVG, MVG, LVG and costumer plant grid, CPG, are presented through ellipse plots. Primary and secondary control loops are represented with lines, while the respective control areas for the secondary control are represented through the surfaces. Figure 6(a) shows an overall view of the power grid, where may be distinguished two areas; the horizontal and the vertical one. HVG (i) areas are set horizontally. They are connected i.e. linked with each other via interconnections. The successively connected MVGs, LVGs and CPGs areas are set vertically. Figure 6(b) shows details of the

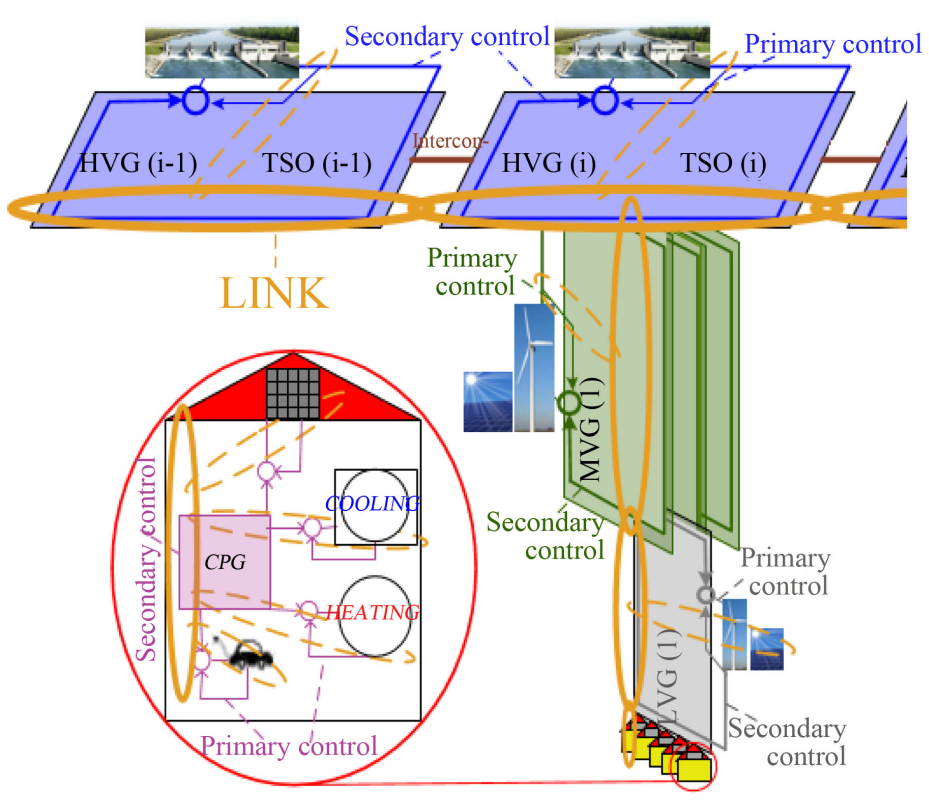

(a)

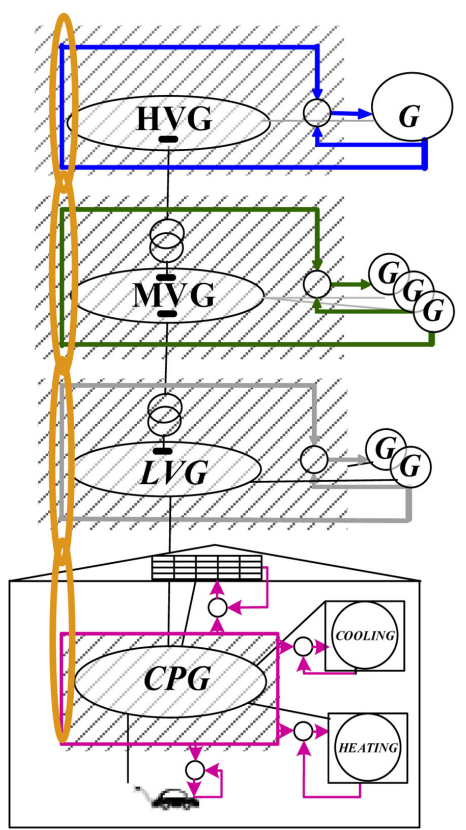

(b)

Figure 6. Global outline of an interconnected power system: (a) overall view; (b) details of vertical axis. 
vertical axis. Over each of grid parts is set a Link named HV-, MV-, LV-, and CP-Link. The secondary control loops of the different grid-Links are interacting in a flexible way with each other like the links in a chain.

\subsection{Volt/var Interaction Chain}

According to the LINK-based architecture [31] Volt/var secondary control loops, VVSC, are outlined on each grid part (be HVG, MVG, LVG and CPG), thus creating a Volt/var interaction chain. Figure 7 shows a schematic presentation of the resilient Volt/var control chain on atypical European power system. As mentioned above, transmission grids are under the administration and operation of TSOs, while the sub-transmission and the distribution ones are under the administration and operation of DSOs. Each of them have the own operation

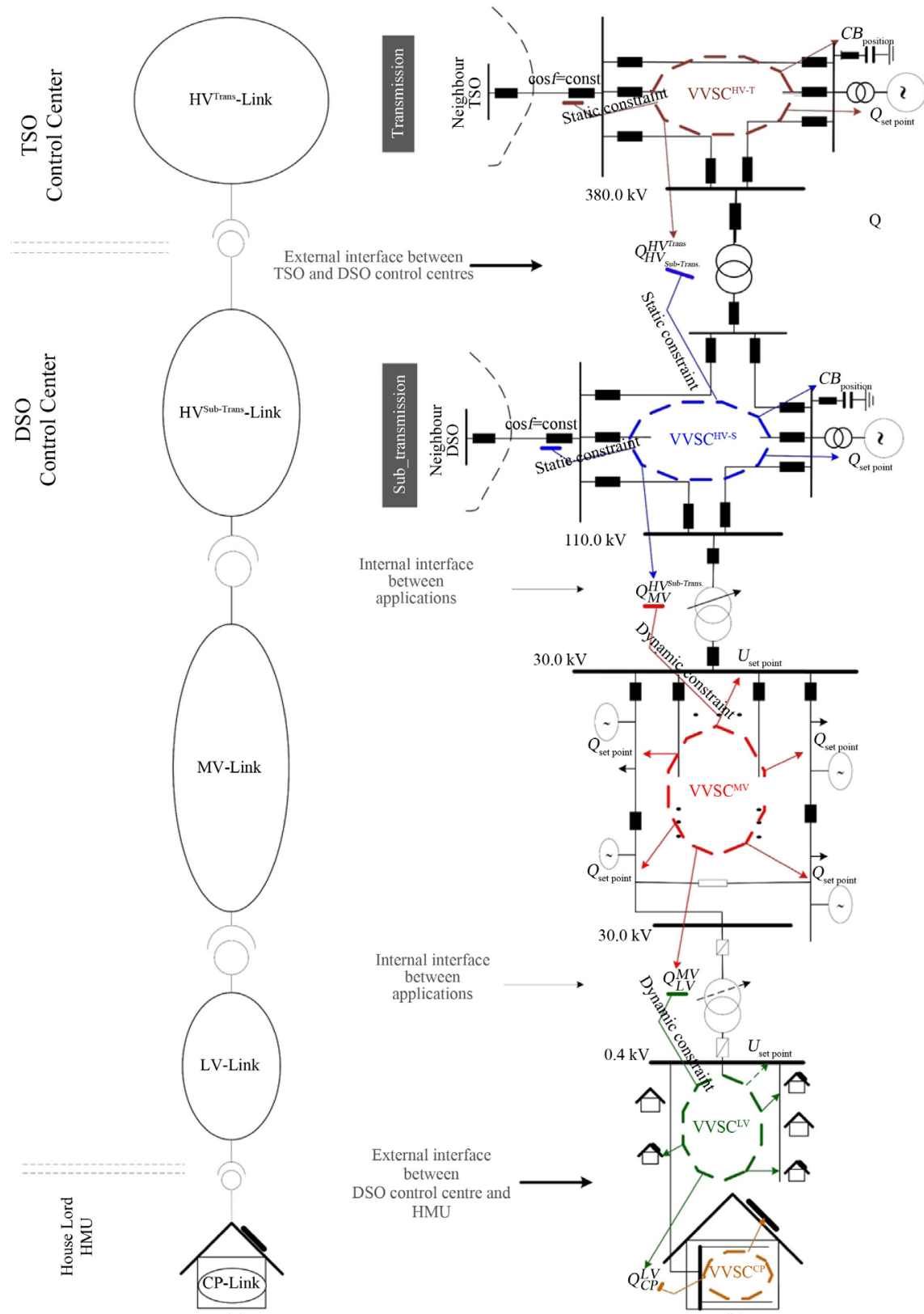

(a)

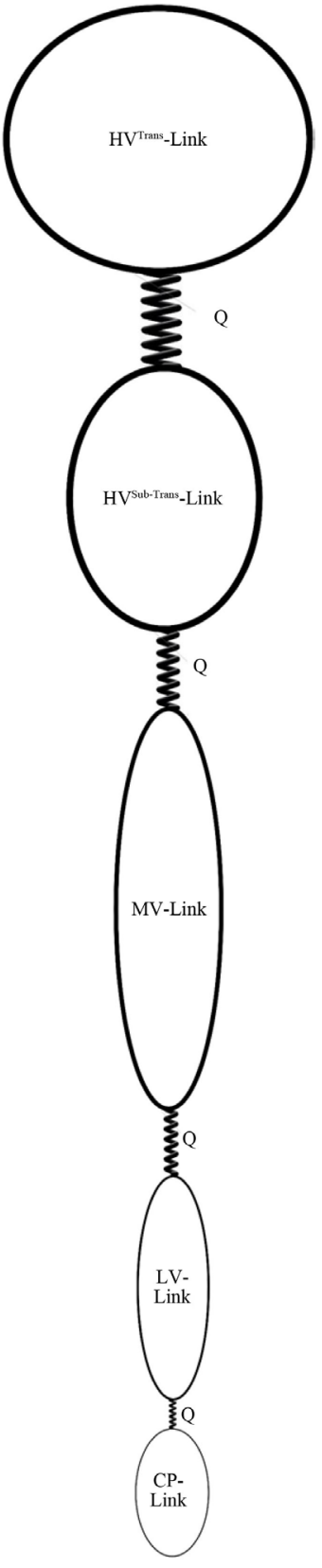

(c)

Figure 7. Schematic presentation of the resilient Volt/var secondary control chain: (a) link structure; (b) Volt/var control loops; (c) resilient connection over the reactive power. 
control center. Figure 7(a) shows the Link structure of the European power grid. Over the transmission grid (very high and high voltage grid) is set an $\mathrm{HV}^{\text {Trans }}$-Link. Over the distribution grid are set three types of Links: 1) $\mathrm{HV}^{\text {Sub-Trans }}$-Link is set over the sub-transmission grid (HVG); 2) MV-Link is set over the MVG; 3) LV-Link is set over LVG. While over the households is set a CP-Link. In view of the network management can be defined two types of interfaces: external and internal. The external interfaces are set between different Links, which have different owners i.e. between TSO and DSO. They are subject to the data security and privacy because the data exchanges between two different companies. Internal interfaces are set between different Links, which have the same owner. In this case the DSO. They are subject only to the data security. That means interfaces between $\mathrm{HV}^{\text {Trans }}$-Link and $\mathrm{HV}^{\text {Sub-Trans }}$-Link are external, while interfaces between the HV-, MV- and LV-Link are internal. The interface between the LV-Link and the CP-Link is an external one, because the information is exchanged between the DSO, and the house lord, or specifically the house management units, HMU. Figure 7(b) shows the VVSC loops of each Link: VVSC ${ }^{\mathrm{HV}-\mathrm{T}}$, VVSC ${ }^{\mathrm{HV}-\mathrm{S}}$, VVSC ${ }^{\mathrm{MV}}$, VVSC ${ }^{\mathrm{LV}}$ and $\mathrm{VVSC}^{\mathrm{CP}}$. Each VVSC application calculates the relevant set points by optimizing its own decisions that are subject to:

- Its own constraints,

- Dynamic constraints that are imposed from neighbor Links.

Dynamic constraints are used to control the reactive power flow in a VVSC chain [13]. They are called dynamic constraints, because they change or should be recalculated in real time depending on the current situation. For ex.: if the reactive power $Q^{\mathrm{HV} \rightarrow \mathrm{MV}}$ delivered from the sub-transmission grid, $\mathrm{HV}^{\text {Sub-Trans }}$-Link, into the distribution grid, MV-Link, should be reduced by $40 \%$, a new desired value will be sent to the VVSC ${ }^{\mathrm{MV}}$ to recalculate the set points by respecting the new $Q^{\mathrm{HV} \rightarrow \mathrm{MV}}$ constraint. Otherwise, if the actual $Q^{\mathrm{HV} \rightarrow \mathrm{MV}}$ is not optimal for the MV-Link operation a request will be sent to the HV-Link to change it and so on. The same schema is foreseen to work over the entire VVSC chain. It is precisely this permanent exchange of desired reactive power $Q$ between different VVSC loops, which creates a resilient interaction between them. Figure 7(c) gives a schematic presentation of the resilient interaction within the VVSC chain by means of the reactive power exchange.

\subsection{Generalized Volt/var Secondary Control}

VVSC is set for all different types of Grid-Links and its algorithm is generalized. Table 1 shows the control variables and constraints of concatenated VVSC. Control variables are the reactive power of generators, inverters and synchronous condenser; the switch position of capacitors and coils and the transformer tap step. The usual constraints are device constraints like PQ diagrams of generators, DGs and inverters, maximal step number of transformers, installed rating of capacitors and coils. Additionally, dynamic grid controls are introduced to enable a resilient interaction of the different VVSC loops on the chain. Reactive power exchanges between neighbor Links makes up the dynamic grid controls. They have a double nature, because they can be converted from grid control variable to grid constraint in dependence of the action, which have to be performed. For ex. VVSC ${ }^{\mathrm{MV}}$ calculations shows that the actual $Q^{\mathrm{HV} \rightarrow \mathrm{MV}}$ (actual) is not optimal for the MV-Link operation. A new set point $Q^{\mathrm{HV} \rightarrow \mathrm{MV}}$ (new) is calculated. In this case the reactive power $Q^{\mathrm{HV} \rightarrow \mathrm{MV}}$ is used by $\mathrm{VVSC}^{\mathrm{MV}}$ as control variable. MV-Link sends a request to $\mathrm{HV}^{\mathrm{Sub}-\text { Trans }}$-Link to change it. VVSC ${ }^{\mathrm{HV}-\mathrm{S}}$ checks the new request by treating the $Q^{\mathrm{HV} \rightarrow \mathrm{MV}}$ as constraint and vice versa. Thus grid controls are set in dynamic lists.

Figure 8 shows the algorithm of the generalized, concatenated VVSCs. One of the three triggers periodic, spontaneous or manual-request initiates the calculation of the grid status, which in the best case is a state estimator [33]. Operation limits are verified. If there are no limit violations, then the optimal operation conditions are checked, ex. loss minimization. If the grid is operating optimally, then no action is necessary. If limit violations or not optimal operation is identified than VVSC starts calculations after having updated the dynamic lists of grid controls.

Table 1. Variables and constraints of concatenated VVSC.

\begin{tabular}{ll}
\multicolumn{1}{c}{ Variables } & \multicolumn{1}{c}{ Constraints } \\
\hline $\begin{array}{l}\text { Operation value of the reactive power } \boldsymbol{Q} \text { (generators, } \\
\begin{array}{l}\text { DGs, inverters, synchronous condenser) } \\
\text { Switch position of capacitors and coils }\end{array}\end{array}$ & $\begin{array}{l}\text { Device constraints (PQ diagrams of generators and inverters, maximal step } \\
\text { number of transformers, installed rating of capacitors and coils) }\end{array}$ \\
$\begin{array}{l}\text { Step position (transformer) } \\
\begin{array}{l}\text { Grid control variables (reactive power } Q \text { between } \\
\text { different Links) }\end{array}\end{array} \quad$ Grid constraints (reactive power $Q$ between different Links) \\
\hline
\end{tabular}




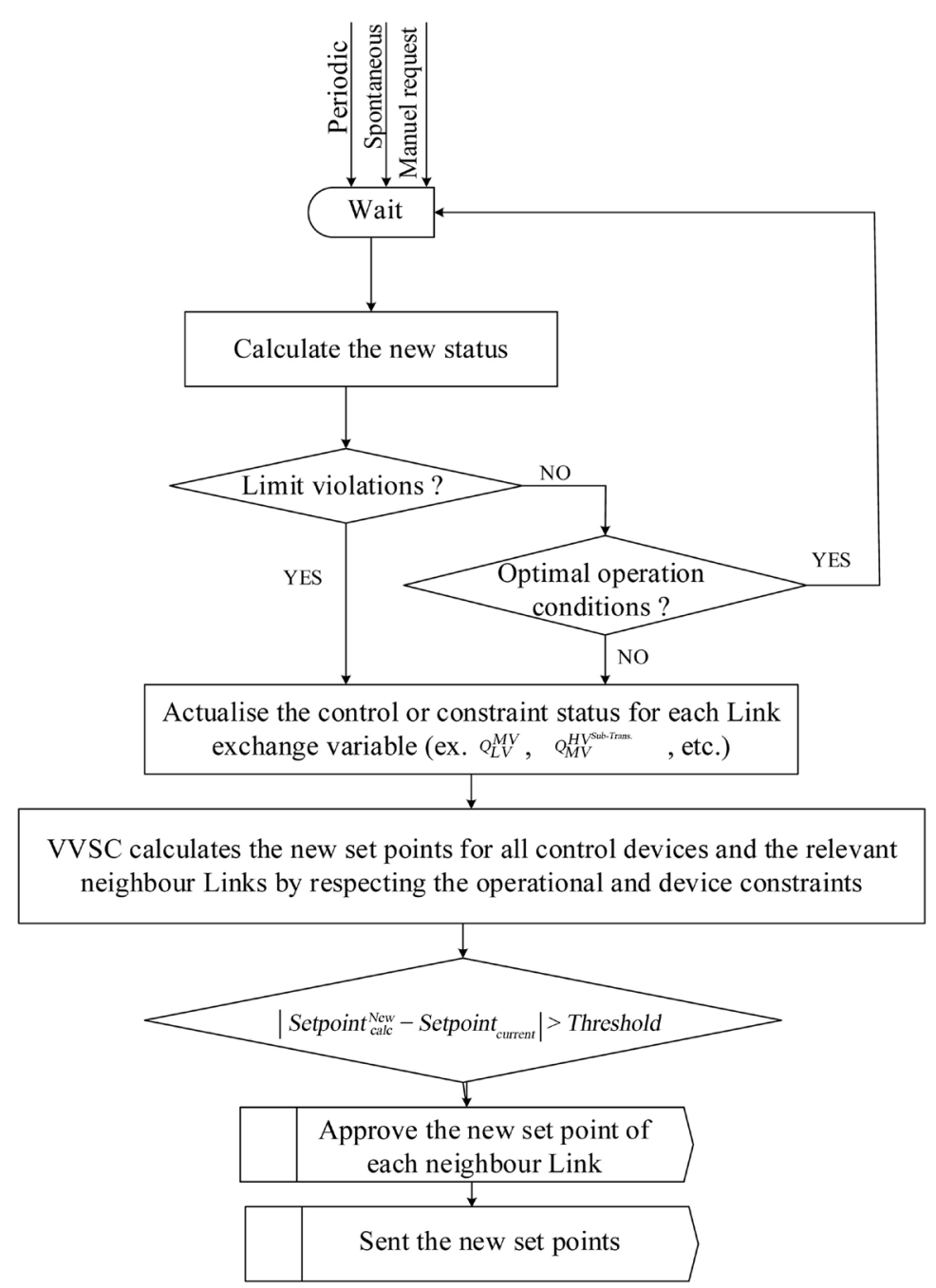

Figure 8. Algorithm of the generalized, concatenated Volt/var secondary control.

Figure 9 shows the use case-voltage violations in a sub-transmission grid. Figure 9(a) shows the system operation in presence of a contingency. Voltage limit violations are discovered on the grid of HV ${ }^{\text {Sub-Trans. }}$ Link. $\mathrm{VVSC}^{\mathrm{HV}-\mathrm{S}}$ application is run to find an adequate solution without violations. Figure 9(b) shows the calculation of the new set points and the corresponding change request. If no any solution is found, than VVSC ${ }^{\mathrm{HV}-\mathrm{S}}$ relaxes the operation constraint on point $\mathrm{B}$. The grid control variable changes the status from grid constraint to grid control variable. $\mathrm{VVSC}^{\mathrm{HV}-\mathrm{S}}$ calculates the suitable and the $\mathrm{HV}^{\text {Sub-Trans. }}$ Link sends a request to the $\mathrm{HV}^{\text {Trans }}$-Link. $\mathrm{HV}^{\text {Trans }}$-Link activates the VVSC ${ }^{\mathrm{HV}-\mathrm{T}}$ and updates the dynamic list grid controls. New reactive power value on point A acts now as constraint. VVSC ${ }^{\mathrm{HV}-\mathrm{T}}$ performs the new calculations. If results are reasonable $\mathrm{HV}^{\text {Trans }}$-Link approves the new desired value. Figure 9(c) shows approving and setting process of the new desired set point. The same procedure is used to alleviate the violations or to optimize the operation in other Link types (other grid parts).

\section{Conclusions}

Reactive power injection on radial configurations has a local and a global effect. The impact extent of both effects on voltage depends on the fact whether the in-between transformers have OLTC or not.

The global effect of the reactive power injection in radial structures at higher voltage levels is always present, and is independent of the fact whether the in-between transformers have OLTC or not. 

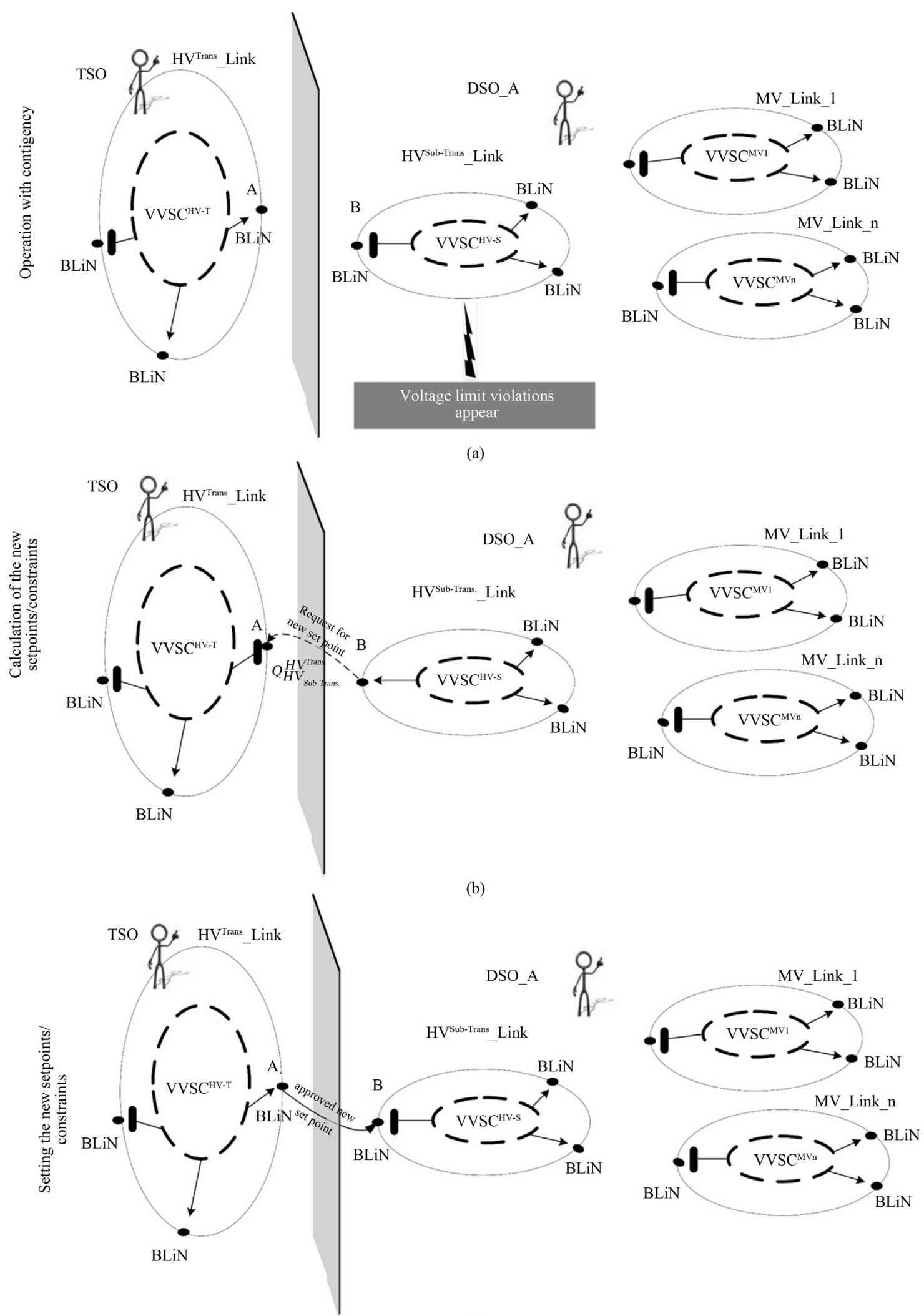

(c)

Figure 9. Use case-voltage violations in the sub-transmission grid: (a) operation with contingency; (b) calculation and change request of the new set points/constraints; (c) approving and setting of the new set points/constraints. 
The global effect of the reactive power injection in radial structures at the bus bar where are connected all feeders (low voltage bus bar of transformer) disappears when the in-between transformers have OLTC. In this case, the global effect can be identified only as long as the impact of global effect on voltage is smaller than the tap step size. If the global effect on voltage is larger than the tap step size, the OLTC will jump into the next tap position and the global effect will disappear.

The global effect of the reactive power injection in radial structures at the bus bar where are connected all feeders (low voltage bus bar of transformer) is present when the in-between transformers do not have OLTC.

The local effect of the reactive power injection on the injection point is always present and is larger when the in-between transformers have OLTC.

To increase the DG share on every distribution voltage level (be medium or low voltage) and to guarantee a stable operation of the power grid, the implementation of the Volt/var secondary control chain at all voltage levels (high-, medium-, low voltage level, and costumer plants) is proposed. The targets of the traditional Volt/var algorithm are extended to ensure a resilient Volt/var interaction chain.

\section{References}

[1] Witzmann, R., Esslinger, P., Grass, N., Girstl, S., Keck, R. and Adelmann, A. (2011) Improving Power Quality and Capacity in Low Voltage GRIDS with Decentral Power Generation Using Intelligent Inverters. IETG Kongress, 08-09 November 2011, Würzburg, Germany, 1-6.

[2] Bertani, A., Borghetti, A., Bossi, C., De Biase, L., Lamquet, O., Massucco, S., Morini, A., Nucci, A.A., Paolone, M., Quaia, E. and Silvestro F. (2006) Management of Low Voltage Grids with High Penetration of Distributed Generation: Concepts, Implementations and Experiments. CIGRE 2006, Canada, 1-6 October 2006, 1-13.

[3] Taljan, G., Krasnitzer, M., Strempfl, F. and Jarz, A. (2012) Spannungsregelung im 30kV Netz UW Judenburg/West Lö-sungsansätze mit Smart Grids. 12. Symposium Energieinnovation, 15-17 Februar 2012, Graz, Austria, 1-9.

[4] Prochazka, K., Kysnar, F., Mezera, D., Vaculik, P. and Novotny, J. (2013) Voltage Quality and Reactive Power Flow Solution in Distribution Networks with a High Share of Renewable Energy Sources. CIRED 2013, Stockholm, Sweden, 10-13 June 2013, Paper No. 1142, 1-4.

[5] Elbs, C. (2014) Netzeinsparungsmöglichkeiten und Erfahrungen einer realen Q(U)-Einführung bei PV Wechselrichtern im Bundesland. Smart Grid Week [Online], 19-23 May, Graz, Austria.

[6] Lund, P. (2007) The Danish Cell Project-Part 1: Background and General Approach. IEEE Power Engineering Society General Meeting, Tampa, Fl, USA, 24-28 June 2007, 1-6.

[7] Schäfer, P., Vennegeerts, H., Krahl, S. and Moser, A. (2015) Derivation of Recommendations for the Future Reactive Power Exchange at the Interface between Distribution and Transmission Grid. CIRED 2015, Lyon, France, 15-18 June 2015, 1-7.

[8] Schäfer, P., Krahl, S., Vennegeerts, H. and Moser, A. (2013) Spannungsebenen Übergreifendes Regelungskonzept für Blindleistung. ETG Congress, 5-6 November 2013, Berlin, Germany, 1-8.

[9] Martensen, N., Kley, H., Cherian, S., Pacific, O. and Lund, P. (2009) The Cell Controller Pilot Project: Testing a Smart Distribution Grid in Denmark. Proceedings of the Grid Interop. 2009: The Road to an Interoperable Grid, Denver, USA, 17-19 November 2009, 216-222.

[10] Hidayatullah, N.A., Paracha, Z.J. and Kalam, A. (2011) Impact of Distributed Generation on Smart Grid Transient Stability. Smart Grid and Renewable Energy Journal, 2, 99-109. http://dx.doi.org/10.4236/sgre.2011.22012

[11] Prata, R.A. (2006) Impact of Distributed Generation Connection with Distribution Grids-Two Case-Studies. IEEE Power Engineering Society General Meeting, Montreal, 18-22 June, 1-8.

[12] Hidayatullah, N.A., Paracha, Z.J. and Kalam, A. (2009) Impacts of Distributed Generation on Smart Grid. Proceedings of the International Conference of Electrical Energy and Industrial Electronic System, 7-8 December 2009, Malaysia, 218-221.

[13] Ilo, A., Gawlik, W., Schaffer, W. and Eichler, R. (2015) Uncontrolled Reactive Power Flow Due to Local Control of Distributed Generators. CIRED 2015, 15-18 June 2015, Lyon, France, Paper No. 512, 1-5.

[14] Jahangiri, P. and Aliprantis, D. (2013) Distributed Volt/var control by PV inverters. IEEE Transactions on Power Systems, 28, 3429-3439. http://dx.doi.org/10.1109/TPWRS.2013.2256375

[15] Burke, J.J. (1994) Power Distribution Engineering Fundamentals and Applications, Marcel Dekker Inc., New York, USA.

[16] ENTSO-E (2013) Implementation Guideline for Network Code-“Demand Connection”. https://www.entsoe.eu/major-projects/network-code-development/demand-connection/Pages/default.aspx 
[17] Vu, H., Pruvot, P., Launay, C. and Harmand, Y. (1996) An Improved Voltage Control on Largescale Power System. IEEE Transactions on Power Systems, 11, 1295-1303. http://dx.doi.org/10.1109/59.535670

[18] Bridenbaugh, C.J., Di Mascio, D.A. and D’Aquila, R. (1992) Voltage Control Improvement through Capacitor and Transformer Tap Optimization. IEEE Transaction on Power System, 7, 222-227. http://dx.doi.org/10.1109/59.141707

[19] Barruncho, L.M.F., Paiva, J.P.S., Liu, C.-C., Pestana, R. and Vidigal, A. (1992) Reactive Management and Voltage Monitoring and Control. International Journal of Electrical Power \& Energy Systems, 14, 144-157. http://dx.doi.org/10.1016/0142-0615(92)90039-C

[20] Piret, J.P., Antoine, J.P., Stubbe, M., Janssens, N. and Dehce, J.M. (1992) Study of a Centralized Voltage Control Applicable to the Belgian System. CIGRE, Technical Report 39-201.

[21] Ilo, A., Schaffer, W., Rieder, T. and Dzafic, I. (2012) Dynamische Optimierung der Verteilnetze-Closed Loop BetrieBergebnisse. VDE Kongress, Stuttgart, 5-6 November 2012, 184-189.

[22] Borozan, V., Baran, M. and Novosel, D. (2001) Integrated Volt/VAR Control in Distribution Systems. IEEE PES Winter Meeting, 3, 1485-1490. http://dx.doi.org/10.1109/pesw.2001.917328

[23] Uluski, R.W. (2010) VVC in the Smart Grid Era. IEEE PES General Meeting, Minneapolis, 25-29 July 2010, 1-7. http://dx.doi.org/10.1109/pes.2010.5589850

[24] Grainger, J.J. and Civanlar, S. (1985) Volt/var Control on Distribution Systems with Lateral Branches Using Shunt Capacitors and Voltage Regulators Part I: The Overall Problem. IEEE Transactions on Power Apparatus and Systems, PAS-104, 3291-3297. http://dx.doi.org/10.1109/tpas.1985.318842

[25] Roytelman, I., Wee, B.K. and Lugtu, R.L. (1995) Volt/Var Control Algorithm for Modern Distribution Management Systems. IEEE Transaction on Power Systems, 10, 1454-1460. http://dx.doi.org/10.1109/59.466504

[26] Sarac, A. and Stankovic, A. (2009) A Robust Algorithm for Volt/VAR Control. IEEE PES Power System Conference and Exposition, Seattle, 15-18 March 2009, 1-8. http://dx.doi.org/10.1109/psce.2009.4840211

[27] Uluski, B. (2012) Volt-Var Control and Optimization. EUCI-Volt/var Optimization Conference, 11-12 June 2012, Nashville, 1-72.

[28] Ilo, A. (2009) Real Time Voltage Control with TVPP. CIRED 2009, FENIX Tutorial, Prague, 8-11 June 2009, 1-11.

[29] Juamperez, M., Yang, G. and Kjaer, S.B. (2014) Voltage Regulation in LV Grids by Coordinated Volt-Var Control Strategies. Journal of Modern Power Systems and Clean Energy, 2, 319-328. http://dx.doi.org/10.1007/s40565-014-0072-0

[30] Demirok, E., Teodorescu, R., Borup, U., Sera, D. and Rodriguez, P. (2010) Evaluation of the Voltage Support Strategies for the Low Voltage Grid Connected PV Generators. Proceedings of IEEE Energy Conversion Congress and EXposition, Atlanta, 12-16 September 2010, 710-717. http://dx.doi.org/10.1109/ECCE.2010.5617937

[31] Ilo, A. (2016) "Link”-The Smart Grid Paradigm for a Secure Decentralized Architecture. Electric Power Systems Research, 131, 116-125. http://dx.doi.org/10.1016/j.epsr.2015.10.001

[32] Carr, J. and McCall, L.V. (1992) Divergent Evolution and Resulting Characteristics among the World's Distribution Systems. IEEE Transaction on Power Delivery, 7, 1601-1609. http://dx.doi.org/10.1109/61.141880

[33] Ilo, A. (2013) The Energy Supply Chain Net. Energy and Power Engineering Journal, 5, 384-390. http://dx.doi.org/10.4236/epe.2013.55040 http://www.scirp.org/journal/PaperInformation.aspx?PaperID=34182 
Appendix

\section{A. European Type 34.5 kV/11 kV 41_Bus Test Case}

Loads connected on buses 13,14 and 16 are modelled as constant power in Figure 10, while the other ones are modelled by means of polynomial equations of the second degree as follow

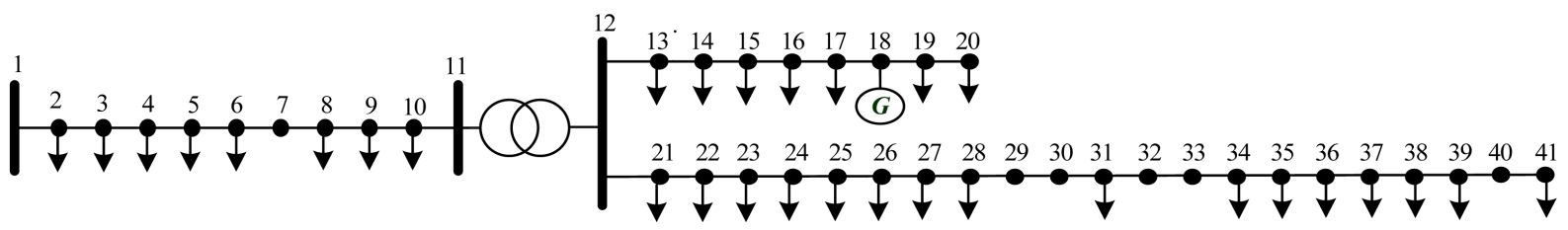

Figure 10. One-line diagram of the 33 kV/10 kV 39_Bus test case, European type.

$$
\begin{aligned}
& P=K_{0}+K_{1} \cdot U+K_{2} \cdot U^{2} ; \\
& Q=K_{0}+K_{1} \cdot U+K_{2} \cdot U^{2}
\end{aligned}
$$

where $K_{0}=0.1, K_{1}=0.3$ and $K_{2}=0.6$.

\begin{tabular}{|c|c|c|c|c|c|}
\hline Brunch & Brunch_type & Un [kV] & R [p.u.] & X [p.u.] & B [p.u.] \\
\hline $1-2$ & Line & 33 & 0.000055 & 0.000143 & 0.19 \\
\hline $2-3$ & Line & 33 & 0.000165 & 0.00043 & 0.572 \\
\hline $3-4$ & Line & 33 & 0.000275 & 0.000716 & 0.954 \\
\hline $4-5$ & Line & 33 & 0.000071 & 0.000186 & 0.248 \\
\hline $5-6$ & Line & 33 & 0.000137 & 0.000358 & 0.477 \\
\hline $6-7$ & Line & 33 & 0.000247 & 0.000645 & 0.857 \\
\hline $7-8$ & Line & 33 & 0.000316 & 0.000824 & 1.097 \\
\hline $8-9$ & Line & 33 & 0.000398 & 0.001039 & 1.383 \\
\hline $9-10$ & Line & 33 & 0.000151 & 0.000394 & 0.525 \\
\hline $10-11$ & Line & 33 & 0.000124 & 0.000322 & 0.429 \\
\hline $11-12$ & Transformer & $33 / 11$ & 0.000001 & 0.000534 & 0 \\
\hline $12-13$ & Line & 11 & 0.002020 & 0.005117 & 0 \\
\hline $13-14$ & Line & 11 & 0.000607 & 0.001562 & 0.0065420 \\
\hline $14-15$ & Line & 11 & 0.000607 & 0.001562 & 0.006542 \\
\hline $15-16$ & Line & 11 & 0.001675 & 0.001905 & 0.005655 \\
\hline $16-17$ & Line & 11 & 0.001675 & 0.001905 & 0.005655 \\
\hline $17-18$ & Line & 11 & 0.001675 & 0.001905 & 0.005655 \\
\hline $18-19$ & Line & 11 & 0.001675 & 0.001905 & 0.005655 \\
\hline $19-20$ & Line & 11 & 0.000607 & 0.001562 & 0.006542 \\
\hline $12-21$ & Line & 11 & 0.001795 & 0.004453 & 0 \\
\hline $21-22$ & Line & 11 & 0.000476 & 0.001282 & 0.006542 \\
\hline $22-23$ & Line & 11 & 0.000476 & 0.001282 & 0.006542 \\
\hline
\end{tabular}

\section{B. Input Data}




\section{Continued}

\begin{tabular}{|c|c|c|c|c|c|}
\hline $23-24$ & Line & 11 & 0.000885 & 0.001480 & 0.005655 \\
\hline $24-25$ & Line & 11 & 0.000885 & 0.001480 & 0.005655 \\
\hline $25-26$ & Line & 11 & 0.000885 & 0.001480 & 0.005655 \\
\hline $26-27$ & Line & 11 & 0.000895 & 0.001635 & 0.006804 \\
\hline $27-28$ & Line & 11 & 0.000476 & 0.001282 & 0.006542 \\
\hline $28-29$ & Line & 11 & 0.000476 & 0.001282 & 0.006542 \\
\hline $29-30$ & Line & 11 & 0.000476 & 0.001282 & 0.006542 \\
\hline $30-31$ & Line & 11 & 0.001077 & 0.002922 & 0 \\
\hline 31 - 32 & Line & 11 & 0.000607 & 0.001562 & 0.0065420 \\
\hline 32 - 33 & Line & 11 & 0.001113 & 0.002679 & 0 \\
\hline 33 - 34 & Line & 11 & 0.001697 & 0.001939 & 0.006804 \\
\hline $34-35$ & Line & 11 & 0.001499 & 0.001704 & 0.005060 \\
\hline $35-36$ & Line & 11 & 0.000607 & 0.001562 & 0.0065420 \\
\hline $36-37$ & Line & 11 & 0.000607 & 0.001562 & 0.0065420 \\
\hline 37 - 38 & Line & 11 & 0.001675 & 0.001905 & 0.005655 \\
\hline 38 - 39 & Line & 11 & 0.001212 & 0.003070 & 0 \\
\hline $39-40$ & Line & 11 & 0.001212 & 0.003070 & 0 \\
\hline $40-41$ & Line & 11 & 0.001675 & 0.001905 & 0.005655 \\
\hline
\end{tabular}

\section{Simulation Results}

\begin{tabular}{|c|c|c|c|c|c|c|}
\hline \multirow[b]{2}{*}{ Bus } & \multirow[b]{2}{*}{$\mathbf{U}[\mathbf{k V}]$} & \multirow[b]{2}{*}{ Load/inj [kW; kvar] } & \multicolumn{2}{|c|}{ Without LTC-fix tap position } & \multicolumn{2}{|c|}{ With OLTC_-variable tap position } \\
\hline & & & $\mathbf{U}[\mathbf{k V}]$ & Load/inj [kW; kvar] & $\mathbf{U}[\mathbf{k V}]$ & Load/inj [kW; kvar] \\
\hline $1^{*}$ & 36.3 & - & 36.3 & - & 36.3 & - \\
\hline 2 & 36.170 & $-276.61 ;-264.24$ & 36.136 & $-278.19 ;-263.61$ & 36.131 & $-276.14 ;-283.76$ \\
\hline 3 & 35.792 & $-330.42 ;-205.05$ & 35.654 & $-306.3 ;-191.17$ & 35.632 & $-330.18 ;-204.9$ \\
\hline 4 & 35.174 & $-1295.05 ;-603.46$ & 34.863 & $-1277.24 ;-792.28$ & 34.815 & $-1275.15 ;-790.97$ \\
\hline 5 & 35.088 & $-1286.94 ;-796.37$ & 34.674 & $-1166.61 ;-785.61$ & 34.617 & $-1164.14 ;-784.12$ \\
\hline 6 & 34.776 & $-976.64 ;-605.6$ & 34.332 & $-955.28 ;-592,03$ & 34.264 & $-953.02 ;-590,63$ \\
\hline 7 & 34.359 & - & 33.757 & - & 33.666 & - \\
\hline 8 & 33.824 & $-929.17 ;-579.57$ & 33.018 & $-941.31 ;-583.28$ & 32.897 & $-937.31 ;-550.77$ \\
\hline 9 & 33.207 & $-950.46 ;-589.03$ & 32.143 & $-904.37 ;-560.08$ & 31.985 & $-899.26 ;-556.88$ \\
\hline 10 & 32.996 & $-941.52 ;-583.41$ & 31.833 & $-891.48 ;-551.97$ & 31.661 & $-885.99 ;-546.52$ \\
\hline 11 & 32.843 & - & 31.598 & - & 31.415 & - \\
\hline 12 & 11.540 & - & 10.881 & - & 11.478 & - \\
\hline 13 & 11.456 & $-432.0 ;-126.0$ & 10.534 & $-432.0 ;-126.0$ & 11.149 & $-432.0 ;-126.0$ \\
\hline 14 & 11.446 & $-414.0 ;-165.0$ & 10.417 & $-414.0 ;-165.0$ & 11.037 & $-414.0 ;-165.0$ \\
\hline 15 & 11.448 & $-909.32 ;-299.06$ & 10.316 & $-776.79 ;-254.92$ & 10.939 & $-849.77 ;-279.25$ \\
\hline
\end{tabular}




\section{Continued}

\begin{tabular}{|c|c|c|c|c|c|c|}
\hline 16 & 11.640 & $-990.0 ;-262.0$ & 10.372 & $-990.0 ;-262.0$ & 10.990 & $-990.0 ;-262.0$ \\
\hline 17 & 11.902 & $-740.14 ;-439.77$ & 10.525 & $-613.37 ;-363.53$ & 11.128 & $-668.96 ;-396.99$ \\
\hline 18 & 12.228 & $8000 ; 0$ & 10.755 & $8000 ;-3000$ & 11.343 & $8000 ;-3000$ \\
\hline 19 & 12.183 & $-307.11 ;-162.54$ & 10.714 & $-252.04 ;-149.44$ & 11.299 & $-274.05 ;-162.68$ \\
\hline 20 & 12.173 & $-306.69 ;-190.4$ & 10.705 & $-251.69 ;-155.87$ & 11.290 & $-273.67 ;-169.67$ \\
\hline 21 & 11.540 & $-331.32 ;-96.68$ & 10.881 & $-302.65 ;-66.21$ & 11.478 & $-328.62 ;-95.89$ \\
\hline 22 & 11.350 & $-313.44 ;-123.92$ & 10.697 & $-286.27 ;-113.04$ & 11.288 & $-310.88 ;-122.9$ \\
\hline 23 & 11.261 & $-677.35 ;-266.43$ & 10.611 & $-801.2 ;-263.06$ & 11.199 & $-870.19 ;-266.05$ \\
\hline 24 & 11.177 & $-621.89 ; 160.69$ & 10.530 & $-566.93 ;-146.49$ & 11.116 & $-616.72 ;-159.36$ \\
\hline 25 & 10.983 & $1026.23 ;-265.17$ & 10.342 & $-935,41 ;-241.7$ & 10.922 & $-1017.69 ;-262.96$ \\
\hline 26 & 10.898 & $-1016.41 .-262.63$ & 10.259 & $-926.33 ;-239.36$ & 10.837 & $-1007.94 ;-260.44$ \\
\hline 27 & 10.828 & $-741.48 ;-191.6$ & 10.191 & $-675.72 ;-174.6$ & 10.767 & $-735.3 ;-190.0$ \\
\hline 28 & 10.789 & $-671.59 ;-195.88$ & 10.153 & $-611.99 ;-178.5$ & 10.728 & $-665.98 ;-194.14$ \\
\hline 29 & 10.758 & - & 10.123 & - & 10.698 & - \\
\hline 30 & 10.736 & - & 10.102 & - & 10.676 & - \\
\hline 31 & 10.702 & $-317.81 ;-82.12$ & 10.068 & $-289.54 ;-74.82$ & 10.642 & $-315.15 ;-81.43$ \\
\hline 32 & 10.658 & - & 10.026 & - & 10.598 & - \\
\hline 33 & 10.598 & - & 9.968 & & 10.538 & \\
\hline 34 & 10.484 & $-222.09 ;-67.99$ & 9.968 & $-202.27 ;-52.27$ & 10.538 & $-220.13 ;-56.91$ \\
\hline 35 & 10.400 & $-219.45 ;-56.7$ & 9.858 & $-199.83 ;-51.64$ & 10.425 & $-217.6 ;-56.23$ \\
\hline 36 & 10.337 & $-217.48 ;-56.2$ & 9.776 & $-198.02 ;-51.17$ & 10.340 & $-215.65 ;-55.72$ \\
\hline 37 & 10.268 & $-215.35 ;-55.65$ & 9.715 & $-196.04 ;-50.66$ & 10.277 & $-213.53 ;-55.16$ \\
\hline 38 & 10.253 & $-214.91 ;-55.53$ & 9.648 & $-195.64 ;-50.55$ & 10.209 & $-213.1 ;-55.06$ \\
\hline 39 & 10.228 & $-214.13 ;-55.33$ & 9.634 & $-194.92 ;-50.37$ & 10.194 & $-212.33 ;-54.86$ \\
\hline 40 & 10.224 & - & 9.610 & - & 10.169 & - \\
\hline 41 & 10.213 & $-136.47 ;-45.44$ & 9.606 & $-126.25 ;-41.36$ & 10.166 & $-137.32 ;-46.05$ \\
\hline
\end{tabular}

* Slack bus bar. 


\section{Submit or recommend next manuscript to SCIRP and we will provide best service for you:}

Accepting pre-submission inquiries through Email, Facebook, LinkedIn, Twitter, etc.

A wide selection of journals (inclusive of 9 subjects, more than 200 journals)

Providing 24-hour high-quality service

User-friendly online submission system

Fair and swift peer-review system

Efficient typesetting and proofreading procedure

Display of the result of downloads and visits, as well as the number of cited articles

Maximum dissemination of your research work

Submit your manuscript at: http://papersubmission.scirp.org/ 